\title{
Damage detection of strengthened RC frame model with FRP sheets under lateral loads
}

\author{
A. Vimuttasoongviriya, N. Kwatra \& M. Kumar \\ Department of Civil Engineering, Thapar University, India
}

\begin{abstract}
For the purpose of assuring seismic safety in north India, it is necessary to monitor the damaged state of existing reinforced concrete (RC) buildings. Nonductile structures often result in the need of strengthening to increase the lateral load carrying capacity. This paper intends to investigate the effect of lateral load on damage indexes of RC frame model strengthened with fiber reinforce polymer (FRP) sheets. Park and Ang damage theory and stiffness damage index method were used. These damage indexes are expressed as a formula based on deformation, energy dissipation and change in stiffness. The damage indexes based on the change in dynamic characteristics namely modal plastic softening index and modal flexibility damage index were used with the help of impact hammer excitation test. Results of this study show that the use of FRP wrapped for structural strengthening provides significant lateral load capacity increases when compared to original specimen. Damage indexes based on deformation and change in stiffness show a much acceptable accuracy correlation with modal parameters indexes in general.
\end{abstract}

Keywords: strengthened RC frame model, FRP sheets, damage indexes, displacement ductility, non-linear FE analysis.

\section{Introduction}

For the purpose of assuring seismic safety, it is necessary to monitor the damaged state of structures. Many existing buildings in north India are nonductile RC structures. These buildings often result in the need of strengthening or retrofitting to increase lateral load carrying capacity. Un-strengthening building may potentially lead to more seismic damage under future earthquake. The strengthening technique using FRP sheets has been successfully used to prevent 
its brittle shear failure and significantly improved the displacement ductility and energy dissipation capacity [8]. This process is also an effective method for upgrading deficient RC connections [9]. FRP wrapped is one popular strengthened method because FRP with epoxy resin have received considerable attention due to its high strength, light weight, quick and easy manageability onsite and high resistance against corrosion [3].

It is necessary to monitor occurrence, location and extent of damage status of structures. The well known damage index is proposed by Park and Ang [11]. This index is calculated as a linear combination of maximum displacement response and total hysteretic energy dissipation. Biddah et al. [1] and Kanwar et al. [5] suggested the method of stiffness damage assessment that explains damage indicator based on changes in structural stiffness. This method is represented by a decrease in stiffness. Damage detection by calculating the change ratio of modal frequency has been widely applied in damage alarming in health monitoring systems of highway bridges [6, 7]. The modal flexibility damage index is the most well known one [10]. The principle of this method is on the basis of the comparison of the flexibility matrices obtained from two sets of mode shapes. Another advantage index is structural ductility. It is used to defined the ability of structure undergo inelastic deformation with stiffness and strength reduction. The collapse of brittle system always occurs suddenly beyond the maximum resistance.

Response of whole RC frame model subjected to external loads is a problem which is important to understand and there is little point in performing analysis without testing since the accuracy of the analysis cannot be verified. This paper intends to investigate both damage detection and effects on strengthened RC frame model under quasi-static load. Finite element (FE) method was used for modelling, nonlinear analysis and results processing of the specimen.

\section{Damage detection methods}

Traditionally, damage indexes have been used to monitor damage status of structures. It expresses performance in terms of a value between 0 (undamaged) and 1 (collapse or ultimate state). The damage detection methods can be calculated as follows.

\subsection{Park and Ang damage index}

Park and Ang [11] have formulated a damage index to estimate the level of damage in RC structures subjected to cyclic loading:

$$
D I_{\text {Park }}=\frac{\delta_{\max }}{\delta_{u}}+\frac{\beta}{\delta_{u} P_{y}} \int d E_{h}
$$

where $\delta_{\max }$ is the maximum experienced deformation, $\delta_{u}$ is the ultimate deformation of the element, $P_{y}$ is the yield strength of the element, $\int d E_{h}$ is the 
hysteretic energy absorbed by the element and $\beta$ is a model constant parameter. $D I_{\text {Park }}$ is combined between the change in deformation ratio and damage due to the energy dissipation. The deformation ratio between ultimate and yield point calls displacement ductility. It is an advantage index to defined structural ability undergoes inelastic deformation with stiffness and strength reduction. Relation between $D I_{\text {Park }}$ and various damage states is presented in table 1 .

Table 1: $\quad$ Relation between $D I$ and various damage states [11].

\begin{tabular}{|c|c|c|}
\hline Damage State & Damage Index, DI & State of Building \\
\hline No Damage & 0.0 & No Damage \\
Slight Damage & $0.0-0.1$ & No Damage \\
Minor Damage & $0.1-0.25$ & Minor Damage \\
Moderate Damage & $0.25-0.4$ & Repairable \\
Severe Damage & $0.4-1.0$ & Beyond Repair \\
Collapse & $>1.0$ & Loss of Building \\
\hline
\end{tabular}

\subsection{Stiffness damage index method}

Biddah et al. [1] proposed stiffness damage index method that uses an indicator based on the relationship between the material stiffness properties of the undamaged and the damaged member of the structure. According to this method severity of damage is expressed as the fractional change in stiffness of an element $[5,12]$ :

$$
D I_{k}=\frac{k_{j}-k_{j}^{*}}{k_{j}}=1-\frac{1}{v_{j}}
$$

where $v_{j}$ is stiffness ratio, $k_{j}$ and $k_{j}^{*}$ are the initial stiffness and damage stiffness of the $j^{\text {th }}$ member. The asterisk (*) denotes the damage state.

\subsection{Dipasquale and Cakmak damage index}

Dipasquale and Cakmak [2] defined the modal plastic softening index for the one-dimensional case, where the fundamental eigen frequency is considered. This damage index is given by

$$
D I_{\text {Dip }}=1-\frac{\omega^{* 2}}{\omega^{2}}
$$

where $\omega$ and $\omega^{*}$ are the fundamental eigen frequency and damage frequency, respectively.

\subsection{Modal flexibility damage index method}

The principle of modal flexibility damage index method is based on the comparison of flexibility matrices obtained from two sets of experimental fundamental frequency and mode shape $[6,13]$. The method is applicable if the 
mode shapes are mass normalized to unity. The damage index for the $l^{\text {th }}$ story using modal flexibility is defined as

$$
D I_{M F D I}=1-\frac{F_{l}}{F_{l}^{*}}=1-\frac{\sum_{i=1}^{N} \phi_{l i}^{2} / \omega_{i}^{2}}{\sum_{i=1}^{N} \phi_{l i}^{* 2} / \omega_{i}^{* 2}}
$$

where $F_{l}$ is the static displacement due to a unit static load applied at the $t^{\text {th }}$ degree of freedom which was used directly as a damage indicator. $\phi_{l i}$ is the $i^{\text {th }}$ mode shape and $\omega_{i}$ is modal frequency.

\section{Experimental setup}

\subsection{Specimen detail and testing procedure}

A three story non-ductile RC moment resisting frame model was manufactured. Beam-column joints were built without transverse reinforcement. Each story was identical in most of the geometrical aspects. The frame model consisted of three slabs $2000 \mathrm{~mm}$ x $2000 \mathrm{~mm}$ x $50 \mathrm{~mm}$. Each column was equally sized rectangular of the cross section $100 \mathrm{~mm} \times 100 \mathrm{~mm}$ (four $8 \mathrm{~mm}$ diameter bars) with height of $950 \mathrm{~mm}$ floor-to-floor. All the beams were equally sized rectangular of $100 \mathrm{~mm}$ x $150 \mathrm{~mm}$ (two $10 \mathrm{~mm}$ diameter bars at the tension and compression faces). All columns and beams were provided with $6 \mathrm{~mm}$ diameter stirrups. Each column cast integrally with $150 \mathrm{~mm}$ x $200 \mathrm{~mm}$ x $400 \mathrm{~mm}$ stub foundation. The stub was in turn bolted firmly on strong floor. The material details, schematic drawing and test set-up of the frame model are presented in table 2 and fig. 1. Each floor was equipped with one displacement dial gauge and one accelerometer of $5 \mathrm{kHz}$ frequency in the horizontal direction. A hydraulic jack of $200 \mathrm{kN}$ capacity was horizontally installed along the desired direction at top floor. The frame model tested under quasi-static loads as shown in fig. 2 to simulate a change in structural damage. After applied each load step, an impact hammer of sensitivity $0.25 \mathrm{mV} / \mathrm{N}$ was used to excite the structure. Before initiating the monitoring calibration of impact hammer and accelerometers was carried out, according to which the sensitivity was assigned to eight channels of the Fast Fourier Transforms (FFT) spectrum analyzer for recording dynamic characteristic data.

Table 2: $\quad$ The details of the materials.

\begin{tabular}{|c|c|c|c|}
\hline \multicolumn{2}{|c|}{ Compressive strength of concrete } & \multicolumn{2}{|c|}{$20 \mathrm{MPa}$} \\
\hline \multirow{3}{*}{$\begin{array}{l}\text { Tensile strength of steel } \\
\text { bars }(\mathrm{MPa})\end{array}$} & Diameter & Yield & Ultimate \\
\hline & $10 \mathrm{~mm}$ & $475.68 \mathrm{MPa}$ & $586.60 \mathrm{MPa}$ \\
\hline & $8 \mathrm{~mm}$ & $516.65 \mathrm{MPa}$ & $628.91 \mathrm{MPa}$ \\
\hline \multicolumn{4}{|c|}{ Mechanical properties of FRP laminate } \\
\hline Thickness & Density & Tensile & $E$ \\
\hline $0.34 \mathrm{~mm}$ & $2.6 \mathrm{~g} / \mathrm{cm}^{3}$ & $3.4 \mathrm{GPa}$ & $63 \mathrm{GPa}$ \\
\hline
\end{tabular}


a)

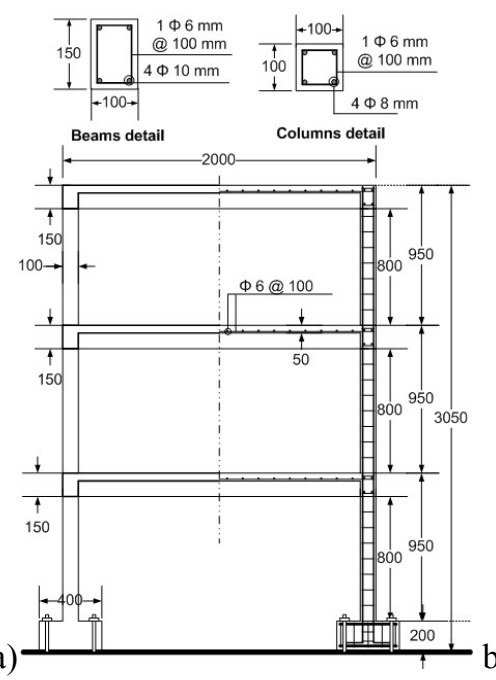

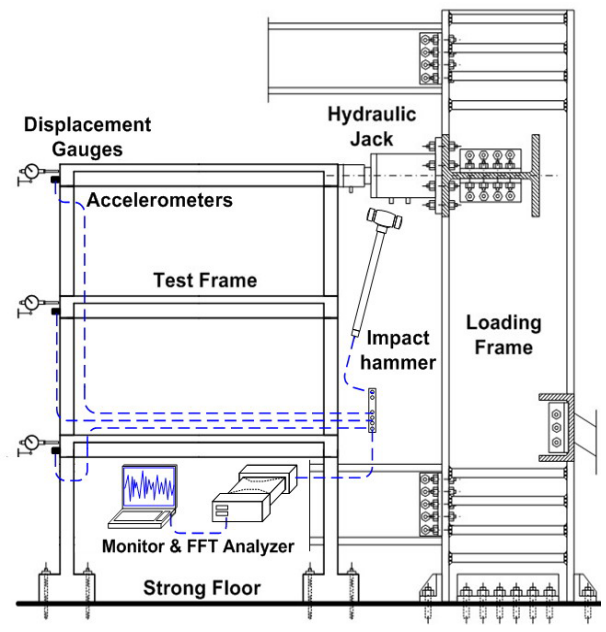

Figure 1: a) Schematic drawing of control frame model and b) experimental test set-up. All dimensions in millimetres.
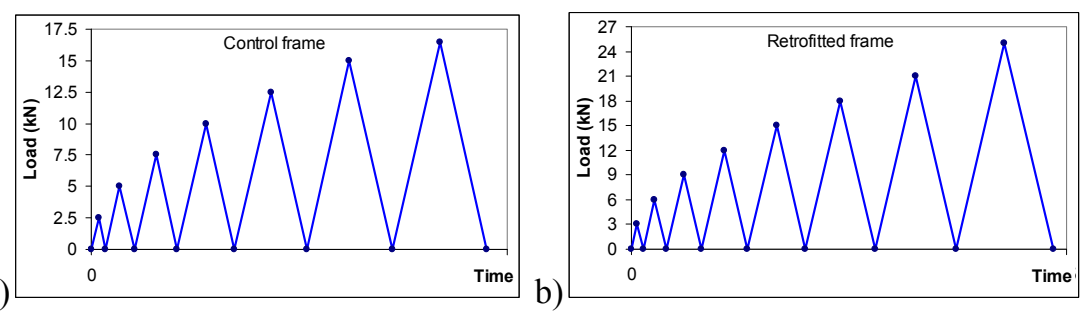

Figure 2: Applied load history: a) control frame and b) strengthened frame.

\subsection{Strengthening scheme}

As earlier explained, the horizontal load was applied to the top floor of the model till the desired damage state was reached. The damaged control frame was then moved back to its initial state. Loose concrete was removed and the surfaces were cleaned of dirt. All the corners of damaged elements were bevelled and rounded to a radius of $10 \mathrm{~mm}$. The small cracks were filled with adhesive epoxy. The concrete surface was applied by adhesive layer of MBrace primer and it was smoothed by MBrace concessive layer. Glass fibre reinforce polymer (GFRP) was used in this paper. Application of FRP wrap provided in two layers on the damaged elements as shown in fig. 3. The first layer was provided with fibre oriented along the beam or column axes, to increase their flexural strength capacity. The columns and beams were confined at each edge zones by wrapping the other layer in the transverse direction as well. 


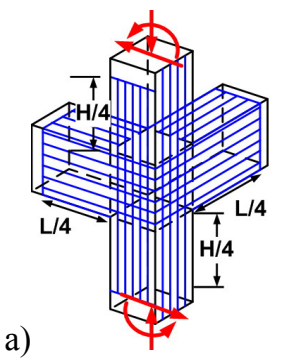

b)

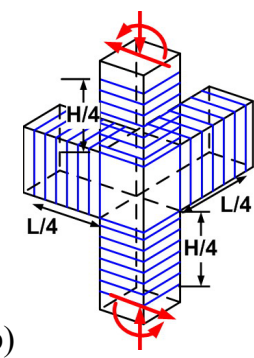

Figure 3: Application of FRP wrap: a) flexural layers and b) confinement layers.

\section{Finite element modelling of retrofitted RC structure}

\subsection{Element types and material properties}

The ATENA nonlinear finite element program (ATENA-3D v4) was used in this study to simulate the behaviour of the RC frame. An eight-node brick element was used to model the concrete. The element is capable of plastic deformation, cracking in three orthogonal directions and crushing. The nonlinear behaviour of compression is following Committee Euro International du Beton model (CEBFIP Code 90). In tension, the stress-strain curve is approximately linearly elastic up to the maximum tensile strength. After this point, the concrete cracks and the strength decrease gradually to zero. The equivalent uniaxial stress-strain diagram for concrete is shown in fig. 4. A polyline element was used to model the steel bars. Two nodes are required for this element. Each node has three degrees of freedom. The steel for the FE models was assumed to be an elastic-perfectly plastic material, Poisson's ratio of 0.3 .

A shell element with 20 nodes, quadratic 3D brick element, was used to model the FRP composite. This element allows for different material layers with different orientations. FRP composite is that consist of two constituents. The

a)

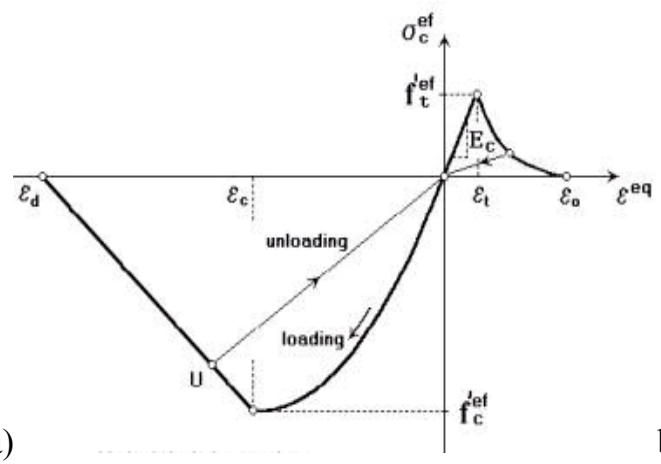

b)

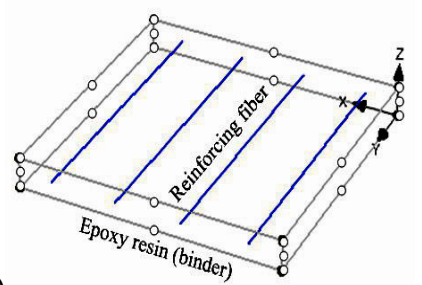

Figure 4: a) Uniaxial stress-strain law for concrete and b) Schematic of FRPs. 
constituents are combined at a macroscopic level and are not soluble in each other. One constituent is the reinforcement, which is embedded in the second constituent of epoxy [4]. The reinforcing material is in the form of anisotropic materials of glass fibers, which are typically stiffer and stronger than the epoxy. Nodes of FRP layered shell elements were connected to those of adjacent concrete solid element in order to satisfy the perfect bond assumption as shown in fig.4. An eight-node brick element was used to model steel plates at the supports.

\subsection{Loading, boundary conditions and nonlinear solution}

By taking advantage of the symmetry of the frame, a symmetrical half of the full frame was used for modeling. The typical steel reinforcement location and strengthened frame for half of the entire model are shown in fig. 5. A one inch thick steel plate was added at the supporting and loading location in order to avoid stress concentration problems. At a plane of symmetry, the displacement in the direction perpendicular to the plane was held at zero. In nonlinear analysis, the loads applied to a finite element model are divided into a series of load increments called load history. The ATENA program uses Newton-Raphson equilibrium iterations for updating the model stiffness. The monitoring points were measured at the same location as for the experimental frame at the middle of each floor, where the largest horizontal displacements can be expected.

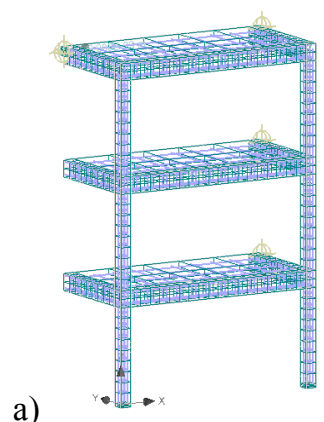

a)

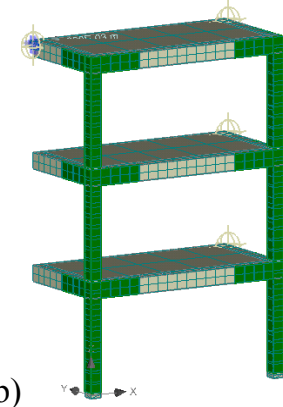

c)

Figure 5: a) The typical steel reinforcement location model, b) strengthened haft frame model and c) experimental strengthened frame model.

\section{Results and discussion}

\subsection{Structural behaviour and damage state of control frame}

The control frame model was constructed. It was loaded in lateral direction at the top floor. Structural stiffness degradation can be observed from the loaddisplacement plot. After applied each load steps, the impact hammer was used to excite the testing frame model. The dynamic characteristics gave the records in FFT analyzer based on linear analysis setup. These records include trigger 
hammer plot, time history plot which give damping, frequency response function (FRF) plot which give the amplitude of vibration along with frequency, respectively. The analyzer was set up to make a free zoom measurement with a frequency range of 0 to $50 \mathrm{~Hz}$. In this frequency range there covered all three majority modes of this frame model. At undamaged state the natural frequency at first, second and third mode were $6.5 \mathrm{~Hz}, 19 \mathrm{~Hz}$ and $31.5 \mathrm{~Hz}$ respectively. The initial diagonal cracks occurred on the beam-column joints of the top floor at a load of $10 \mathrm{kN}, D I_{\text {Park }}$ of $0.32, D I_{k}$ of $0.47, D I_{\text {Dip }}$ of 0.12 and $D I_{M F D I}$ of 0.16 , indicating that the elements of top floor are the most stressed, moderate damage state. At a load of $12.5 \mathrm{kN}$, large cracks started to open and small cracks occurred on connection joins of second floor. It indicated that the yield point was visible at a load $12.5 \mathrm{kN}$, displacement of $31 \mathrm{~mm}$ from initial state, $D I_{\text {Park }}$ of $0.49, D I_{k}$ of $0.57, D I_{D i p}$ of 0.16 and $D I_{M F D I}$ of 0.21 , severe damage state. Ultimate damage state began at the load of $16.5 \mathrm{kN}$ and with a displacement of $69 \mathrm{~mm}$, leading to $D I_{\text {Park }}$ of $0.95, D I_{k}$ of $0.76, D I_{D i p}$ of 0.34 and $D I_{M F D I}$ of 0.34 , respectively. The frequencies at ultimate state of first, second and third mode were $5.2 \mathrm{~Hz}, 15.5 \mathrm{~Hz}$ and $25.9 \mathrm{~Hz}$ respectively. The displacement ductility was nearly 2.22 and total energy dissipation was $567.57 \mathrm{kN}-\mathrm{mm}$. Diagonal cracks occurred on connection zone of each floor and horizontal cracks occurred on columns near stub foundations. Failure mode and load-displacement plot of system are shown in fig. 6 and 7 respectively. Under quasi-static loads of nonductile beam-column joints of this specimen, beams adjoining were subjected to shears and moments. Under these shears and moments, the top and bottom steel bars moved in the opposite direction. These forces were balanced by bond stress developed between concrete and steel bars. In such circumstances, the plastic hinges were formed and connection joints lost their capacity to carry load.

The relation between applied loads and damage indexes of control frame are shown in figs. 8 and 9 and summary in table 3. From these plots, it is worth mentioning here that the health of the non-ductile RC structure is said to be of reduces to more than $50 \%$ of initial state, and when modal parameters damage

a)

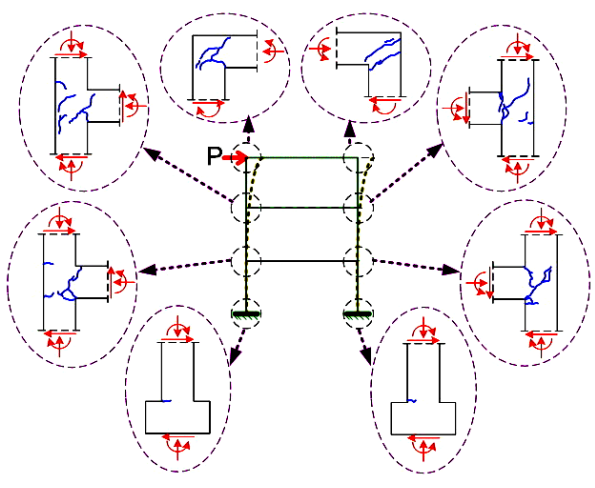

b)

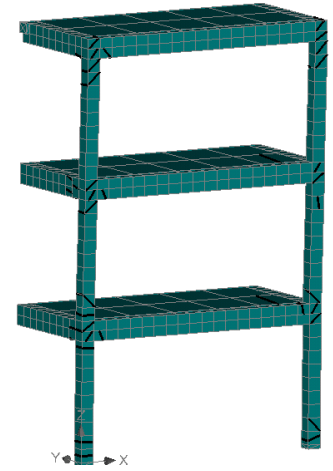

Figure 6: Failure mode of control frame: a) experimental frame, b) FE analysis. 
a)

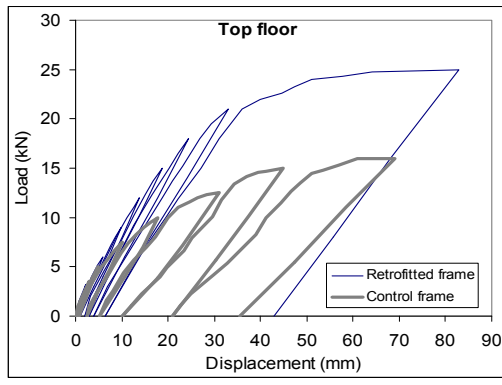

b)

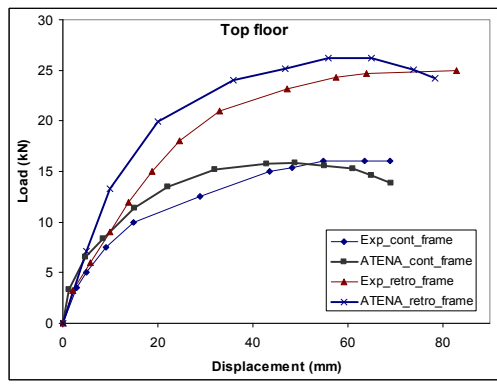

Figure 7: a) Load-displacement plot at top floor and b) comparison between backbone load-displacement plot of FE models and experimental results.

index increases to larger than 0.20 . The vibrational damage detection methods seemed to increase slowly with increase in load. The average changed of corresponding natural frequencies decreased approximately $18.73 \%$. In general, the effects of damaged structure on the changes in natural frequencies are found to be negligible.

Table 3: Damage index of structural system and appearance of control frame.

\begin{tabular}{|c|c|c|c|c|c|c|}
\hline$P(\mathrm{kN})$ & $P / P_{\max }$ & $D I_{k}$ & $D I_{\text {Park }}$ & $D I_{\text {Dip }}$ & $D I_{M F D I}$ & Appearance \\
\hline 0 & 0 & 0 & 0 & 0 & 0 & Un-deformed \\
5.0 & 0.30 & 0.18 & 0.09 & 0.03 & 0.04 & Un-cracked \\
7.5 & 0.45 & 0.25 & 0.18 & 0.06 & 0.09 & Minor cracking \\
10.0 & 0.61 & 0.47 & 0.32 & 0.12 & 0.16 & Moderate cracking \\
12.5 & 0.76 & 0.57 & 0.49 & 0.16 & 0.21 & Severe cracking \\
15.0 & 0.91 & 0.65 & 0.61 & 0.25 & 0.26 & Spalling of concrete \\
16.5 & 1 & 0.76 & 0.95 & 0.34 & 0.34 & cover \\
& & & & & & Loss of shear capacity \\
\hline
\end{tabular}

a)

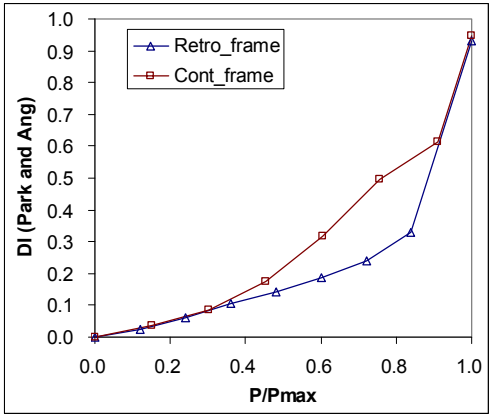

b)

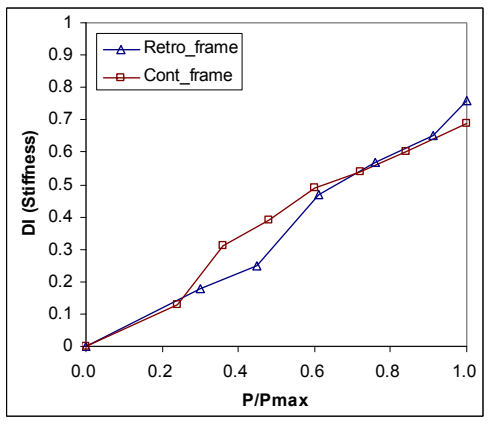

Figure 8: a) Park and Ang damage index and b) Stiffness damage index. 
a)

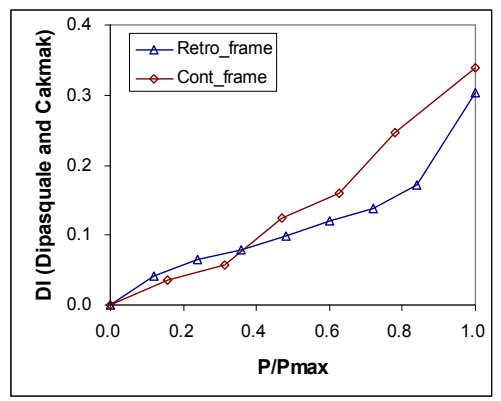

b)

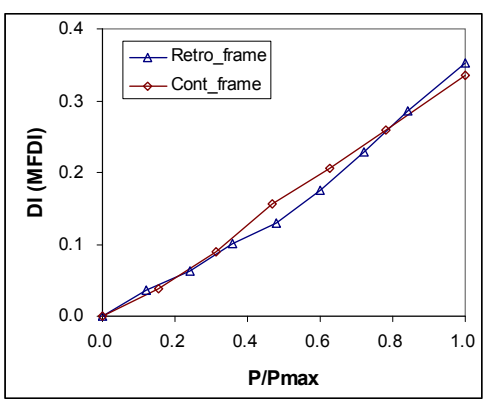

Figure 9: a) Dipasquale damage index and b) Modal flexibility damage index.

\subsection{Structural behaviour and damage state of strengthened frame}

Test for the strengthened frame was performed in the similar manner as that for the control frame. At the final stage of the damaged control frame was grouting cracks by adhesive epoxy and wrapped it with FRP sheets. At initial state the natural frequency at first, second and third mode were $6.7 \mathrm{~Hz}, 20.7 \mathrm{~Hz}$ and 34.0 $\mathrm{Hz}$, respectively. The yield damage state of the strengthened frame was visible at a load $18 \mathrm{kN}$, displacement of $24.8 \mathrm{~mm}, D I_{\text {Park }}$ of $0.24, D I_{k}$ of $0.54, D I_{\text {Dip }}$ of 0.14 and $D I_{M F D I}$ of 0.23 , severe damage state. Moving sound of FRP layers started from this load. Ultimate damage state was at the load of $25 \mathrm{kN}$ at displacement of $83 \mathrm{~mm}$ from initial state and total energy dissipation was $1039.68 \mathrm{kN}-\mathrm{mm}$. The frequencies at first, second and third mode were $5.5 \mathrm{~Hz}, 17.2 \mathrm{~Hz}$ and $29 \mathrm{~Hz}$ respectively. The damage index of $D I_{\text {Park }}$ was $0.93, D I_{k}$ of $0.69, D I_{\text {Dip }}$ of 0.30 and $D I_{M F D I}$ of 0.35 . There were breaking sounds of fibre and epoxy layer from connection joints at ultimate state. Failure mode of strengthened frame was fibre layers slip as shown in fig. 10. The average changed of corresponding natural frequencies decreased approximately $16.51 \%$. The load versus displacement behaviour is shown in fig. 7 along with the behaviour for the control frame. From this figure, the load displacement relation can be roughly considered to be linear when the load is smaller than or equal to $18 \mathrm{kN}$. After remove FRP layers, it was observed that in addition to old cracks which opened up, new flexural cracks also appeared at the connection joints and columns.

The relation between load and the damage indexes of strengthened frame are shown in figs. 8 and 9 and details are presented in table 4. Damage index curves of strengthened frame below the curves of control frame indicating better performance as compare to the control frame. The displacement ductility for strengthened frame was nearly 3.34. It shown that the FRP wrapped around the structural elements in this manner are intended to provide external confinement and crushing of the concrete cover at larger lateral displacements. Experimental results also approved that the use of FRP wrapped for structural strengthening provides significant lateral load capacity increases approximately $151.5 \%$ as compared to control frame. The ductile behaviour of the strengthened frame is largely restored after the FRP composite sheets are engaged. 
Table 4: Damage index of structural system and appearance of retrofitted frame.

\begin{tabular}{|c|c|c|c|c|c|c|}
\hline$P(\mathrm{kN})$ & $P / P_{\max }$ & $D I_{k}$ & $D I_{\text {Park }}$ & $D I_{\text {Dip }}$ & $D I_{M F D I}$ & Appearance \\
\hline 0 & 0 & 0 & 0 & 0 & 0 & Un-deformed \\
3.0 & 0.12 & 0.13 & 0.02 & 0.04 & 0.04 & Un-cracked \\
9.0 & 0.36 & 0.39 & 0.10 & 0.08 & 0.10 & Un-cracked \\
15.0 & 0.60 & 0.49 & 0.19 & 0.12 & 0.18 & Noise of fibre moving \\
18.0 & 0.72 & 0.54 & 0.24 & 0.14 & 0.23 & Severe damage \\
21.0 & 0.84 & 0.60 & 0.33 & 0.17 & 0.29 & Breaking noise of fibre \\
25.0 & 1 & 0.69 & 0.93 & 0.30 & 0.35 & Loss of shear capacity \\
\hline
\end{tabular}

a)
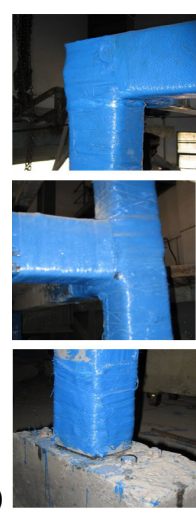

b)

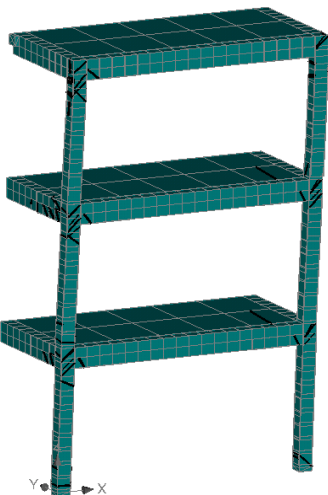

Figure 10: Failure mode of strengthened frame: a) actual frame, b) FE analysis.

\subsection{Results of FE method and comparative analysis}

Developed analytical models were validated by comparing the load-displacement results with existing experimental data. Fig. 7 shows that the backbone loaddisplacement plots from the FE analysis agree well with the experimental results. The model plots were stiffer than that from experimental results. The yield load for the FE analysis of control frame was $13 \mathrm{kN}$, which was higher than the load of $12.5 \mathrm{kN}$ from the experimental results by $4 \%$. Lastly, the ultimate load of $16 \mathrm{kN}$ from model was lower than the ultimate load of $16.5 \mathrm{kN}$ from the experimental data by $3 \%$. Similar to the control frame, the yield load for the model of strengthened frame was $20 \mathrm{kN}$, which was higher than the actual frame of $18 \mathrm{kN}$ by $11.11 \%$. The ultimate load for the model was $26 \mathrm{kN}$, which was higher than the ultimate load of $25 \mathrm{kN}$ for the actual frame by $4 \%$. Figures 6 and 10 show the crack patterns at final state from FE models corresponded well with the observed failure mode of experimental control frame and strengthened frame after remove FRP sheets. 


\section{Conclusion}

Based on the performed research investigation, the following main conclusions can be drawn: 1) Experimental results approve that the use of FRP wrapped for structural strengthening provides increased significant lateral load capacity. 2) The ductile behaviour of the strengthened frame is largely restored after the FRP composite sheets are engaged. 3) The health of RC structures of both original and strengthened specimen seemed to become unsafe when $D I_{\text {Park }}$ and $D I_{k}$ increases larger than 0.5 or dynamical damage indexes increase larger than 0.2 . 4) The damage indexes of strengthened frame reduce indicating better performance as compare to the control frame. 5) Damage indexes based on deformation and change in stiffness show a much acceptable accuracy correlation with dynamical damage indexes in general. 6) Although the stiffness of the damaged RC structure is regained significantly by wrapping FRP jacket but it is not able to bridge the cracks fully. 7) The failure of the strengthened frame is due to breaking up of the bond between FRP layer and concrete. 8) The analytical results and crack patterns from FE method agree well with the experimental results.

\section{References}

[1] Biddah, A., Heidebrecht, A.C. \& Naumoski, N., Use of push over test to evaluate damage of reinforced concrete frame structures subjected to strong seismic ground motions. Proc. of the 7th Canadian Conf. On Earthquake Engineer, Montreal, 1995.

[2] Dipasquale, E.1. \& Cakmak, A.S., On the relation between local and global damage indices. National Center for Earthquake Engineering Research, Technical Report NCEER-89-0034, State University of New York at Buffalo, 1989.

[3] Ghobarah, A. \& Elmandoohgalal, K., Seismic rehabilitation of short rectangular RC columns. Earthquake Engineering, 8(1), pp. 45-68, 2004.

[4] Kachlakev, D. \& Miller, T., Finite element modelling of reinforced concrete structures strengthened with FRP laminates. Final report SPE 316: Oregon and Washington, 2001.

[5] Kanwar, v., Kwatra, N. \& Aggarwal, P., Damage detection for framed RCC buildings using ANN modelling. Damage mechanics. 16(4), pp. 457-472, 2007.

[6] Ko, J.M., Sun, Z.G. \& Ni, Y.Q., Multi-stage identification scheme for detecting damage in cable stayed Kap Shui Mun bridge. Engineering Structures, 24, pp. 857-868, 2002.

[7] Lieven, N.A.J., \& Ewins, D.J., Spatial correlation of mode shapes, the coordinate modal assurance criterion. Proc. of the 6th Int. Conf. on Modal Analysis, pp. 690-695, 1988.

[8] Memon, M.S. \& Sheikh, S.A., Seismic resistance of square concrete columns retrofitted with glass-fiber reinforced polymer. ACI Structural Journal, 102(5), pp. 774-783, 2005. 
[9] Mukherjee, A. \& Joshi, M., FRPC reinforced concrete beam-column joints under cyclic excitation. Composite Structures, 70, pp. 185-199, 2005.

[10] Pandey, A.K. \& Biswas, M., Damage detection in structures using changes in flexibility. Sound and Vibration, 169(1), pp. 3-17, 1994.

[11] Park, Y.J. \& Ang A.H.S., Seismic damage analysis of RC buildings, Structural Engineering, ASCE, 111, pp. 740-757, 1985.

[12] Stubbs, N., Kim, J.T. \& Tapole, K., An efficient and robust algorithm for damage localization in offshore platforms. Proc. of '92 ASCE 10th Structures Congress, Texas, 1992.

[13] Wang, J.F., Lin, C.C. \& Yen, S.M., Story damage index of seismicallyexcited buildings based on modal parameters. Proc. of the 18th Int. Conf. on Structural Mechanics in Reactor Technology, pp. 3278-3289, Beijing, 2005 . 